\title{
Assestment of Grade 5 Social Studies Textbook Content in Light of Teacher Opinios
}

\author{
Necati Tomal \\ Correspondence: Necati Tomal, Ondokuz Mayss University Faculty of Education Department of Social Studies \\ Education Samsun, Turkey.
}

\author{
Received: April 3, $2019 \quad$ Accepted: May 27, $2019 \quad$ Online Published: June 5, 2019 \\ doi:10.11114/jets.v7i7.4314 URL: https://doi.org/10.11114/jets.v7i7.4314
}

\begin{abstract}
There have been significant changes in social studies textbooks through time. Especially since the 2005 syllabus entered into force, these textbooks have seen important changes both in content and form. While comprising of a little citizenship knowledge and mostly history and geography subjects before, since 2005 these textbooks came to contain many fields of knowledge including science and technology, psychology, sociology and economy, in addition to the history and geography subjects before. This new form of the textbooks has also passed through many changes until today. Finally, social studies textbooks were updated in 2018-2019 academic year based on the changes in the program. The goal of this study is to assess the contents of this updated grade 5 social studies textbook in line with opinions of the teachers.

In scope of this study an interview form mostly comprised of open-ended question was applied with 28 teachers working in various provinces in order to assess the contents of the grade 5 social studies textbook put into use in the 2018-2019 academic year. The responses given to these open-ended questions are processed by content analysis method, which is a qualitative research technique. The study process was conducted in a planned and transparent manner. This is also important for reliability and validity of the study.

It is found that teachers are generally satisfied with the content of grade 5 social studies textbook. There are some problems cited in regard of the language of the book not being suitable for the student level in context of some subjects. In particular, teachers have important suggestions regarding use of a storytelling language in regard of culture and heritage subjects in the textbook. The textbook is found adequate in regard of actuality and inner circle teaching. The teacher largely think compatibility of visuals with the content of textbook is sufficient; however, the textbook used in the previous year was also deemed agreeable in this regard.
\end{abstract}

Keywords: textbook, social studies teaching, content

\section{Introduction}

Planned and programmed education and teaching activities start at the school. Computers, blackboards, projectors, smart-boards, scale models and books are some of the equipment and tools used in context of teaching in modern schools. Books have also been one of the primary materials of teaching even at the times technology was not as advanced as today. In our time, where technology is widely used in education in teaching, books are still some of the most important teaching materials. In short, textbooks are essential teaching tools for both teachers who use a large number of materials and teachers who use a small number of materials. Books are easy to access and use. In comparison to other tools they also have very different functions. Due to these characteristics, books are one of most widely used teaching tools (Kılıç, 2007, 26-27). Pinto (2007) also points out another important issue, saying, "appeal or advantage of textbooks is the fact that, unlike other materials, they do not require daily use of a photocopier." Based on these explanations, let us not think of textbooks only as materials used by teachers. Textbooks are an important material for the students as much as they are for the teachers. Keser's $(2004,261)$ statement of "textbook is a written and printed learning-teaching medium" can be taken as a call for attention to the importance of this material for both teachers and students. Textbook is the first book the child possesses and refers to for direction to other books (Baştürk, 2006, 29). Textbook is an important resource where students can find well organised information they need to prepare for lectures and exams. As it can be understood from the explanations above, many sources point out the importance of resource (Ulusoy, 2008; İşsman 2005). Without a doubt a textbook provides a beneficial resource when it is carefully selected; 
however, when the textbook becomes the centre of class activities and pushes the teacher himself to the background, textbook may bring many negative effects in regard of student learning (Ceyhan et al., 2003, 18). In many cases, teachers display a style of teaching giving the impression that the writer of the textbook they use is secretly in command of the class (Küçükahmet, 2004, 11). In short, as stated by Güneș et al. (2010) textbook should not take the teacher hostage (83). Having tried to point out its importance and limitations from various angles in the parts above, we provide some definitions of textbook according to various researchers in the following parts:

Textbook is a resource significantly determining what the students will learn and what the teachers will teach in teaching-learning process, especially in planned education applications (Tertemiz et al., 2004, 34).

As printed teaching tools created to be compatible with the age and knowledge level of students on the basis of teaching programs in knowledge conveyance process in lectures, textbooks are the most widespread teaching materials (Bayrakçı, 2005).

Textbooks is a basic resource printed for teaching of a certain course, for students at a certain level, whose content is prepared, assessed and approved according to the teaching programs (Kılıç, 2006, 40).

Dove (1998) defines textbooks as the main tool of teaching and conveyance of knowledge to students (24).

Textbooks are teaching tools playing an important role in teaching and learning of the content in all fields (Alvermann et al., 1991).

Some researchers have also pointed out some materials like workbooks and guidebooks for the purpose of better utilisation of textbooks by both students and teachers. Students need supplementary books to better utilise textbooks and gain the necessary behaviours. The most fundamental among these supplementary tools is the workbook. Guidebooks for the teachers indicate the activities the teacher should have the students follow, as well as the order and procedure of these activities, helping them to guide the student more swiftly (Kılıç, 2007, 43). Workbooks and guidebook are also prepared for social studies textbooks from time to time. However, the there is no workbook or guidebook for the current social studies textbook. Widely used by teachers, textbooks are teaching tools interpreting syllabus policies. Content of the textbook indicates which knowledge and skills the students should achieve (Pinto, 2007).

Textbooks should display a progress from the student as a passive receiver of knowledge to student as an active researcher of knowledge and help the students to enjoy these materials (Gökkaya, 2003, 14). Textbooks have gone through a change with the social studies teaching programs prepared by a constructivist approach. Textbooks are now designed with an approach leaving intensive information dump method behind, instead picking an approach which provides less information but also indicates ways of accessing more information (Keçe, 2013, 41).

Some characteristics which must be present in social studies textbooks can be listed as follows;

1 - Content must be able to serve student gains.

2 - Content must be prepared according to academic level, interests and expectations of the students.

3 - Content should include examples facilitating learning.

4 - Arrangement of the content should encourage the student to act independently in learning.

5 - Content should be supported by news articles from newspapers, magazines, etc. media as necessary.

6 - Textbook content should be closely related to real life situations.

7 - Textbook content should make use of literary products like stories, myths, poems, folk songs, etc. (Keçe, 2013, 46).

In addition to the points listed above, information in the textbooks being current, complete and accurate, and following the principle of near-to-far in arrangement of the information can be pointed out as other points of importance in arrangement of the content of social studies textbooks. Many researchers point the attention to these characteristics which can be called into question in the context of general teaching principles (Sönmez, 2011; Duman, 2011; Tan, 2012; Arslan, 2012).

In evaluation of social studies textbooks and programs, the year 2005 carries great significance. The social studies teaching program based on the constructivist approach which entered into force in both middle schools and primary schools in 2005 caused fundamental changes in textbooks. The previous textbooks which largely comprised of history and geography subjects were replaced with textbooks rich in visuals and using a playful language, providing less dry knowledge and trying to encourage the student to search for knowledge through the activities we endeavoured to touch on above. Sever et al. (2013) also tries to point out this fact in their study on social studies textbooks, saying, "when compared to textbooks prepared for the previous programs, grade 4-7 social studies textbooks display a rich and qualified look" (20).

Through time there has been many studies regarding social studies textbooks. After the fundamental change in the program in 2005 , the number of studies on social studies textbooks has shown an increase. When we examine these 
studies, we see positive opinions regarding social studies textbooks are prevalent, but there are some problems with their content (Alaca, 2017; Karabacak \& Turan, 2017; Sever \& Koçoğlu, 2013; Gülersoy, 2012; Nalçacı, 2011; İncekara \& Karatepe, 2010; Taş, 2007; Öcal \& Yiğittir, 2007; Önal \& Kaya, 2006). Results of some of the relevant studies will be discussed in the Arguments and Conclusions secions of the study.

\section{Method}

The semi-structured interview method, a qualitative study data collection technique, is used in this study. The reason for organising this study in the form of an interview was the fact that the open-ended questions used in this technique allow deep collection of data. Özgen's (2016) opinion that "unlike quantitative studies focusing on scope or width, the purpose in qualitative studies is to analyse the substance and depth of the subject" summarises our reason to choose interview technique for data collection.

\subsection{Study Group}

Work group comprises of teachers from different provinces, of different genders, seniorities, education levels and departments. These teachers were determined in consideration of maximum diversity in accord with the targeted sampling methods of Paton $(2014,234)$. The total of 28 teachers taking the interview was comprised of 13 teachers from Samsun, 8 teachers from Ağrı and 7 teachers from Erzurum (Turkey). In the total 28 teachers 17 were male. 22 of the teachers have been on duty for 9 years or less. In regard of education level, 23 of the teachers have graduate degrees, while 5 have post-graduate degrees. In addition, 5 of the participating teachers are history teaching department graduates, while 23 are graduates of social studies teaching department. The most important reason for forming the study group from teachers of various characteristics is not to achieve generalisation, but to provide ideological abundance and diversity, thus expanding validity of scope of the study.

\subsection{Data Gathering Tool}

The interview form includes questions regarding personal characteristics of the participants, as well as the open-ended questions. The questions in the data gathering tools were prepared based on an examination of grade 5 social studies textbook and opinions of 3 social studies teachers. In the final stage of preparation of the data gathering tool the interview form was presented for approval of colleagues specialised in social studies teaching. All these processes have helped ensure validity of both the data gathering tool and the study. Validity and reliability of qualitative research should be considered in the context of process, rather than on the context of measure.

\subsection{Analysis and Assessment of Data}

The responses given to these open-ended questions in the interview form are processed by content analysis method, which is a qualitative research technique. Female teachers responding to the open-ended questions were coded as " $\mathrm{K}$ " and male teachers were coded with "E". Female and male teachers were numbered as $\mathrm{K} 1, \ldots$ and $\mathrm{E} 1, \ldots$ in their own groups. In analysis of the responses, each question regarding content of grade 5 social studies textbook and the responses given to that question were classified under certain headings, and frequencies of each heading were determined. Thus, positive and negative aspects related to the textbooks were revealed. In order to better understand the negative aspects of the textbook and their reasons, some responses were cited as is and some assessments and inferences were made on basis of these responses. Examples are provided for these assessments both from responses of participating teachers and from the current social studies textbook. In addition, research findings were also assessed in context of the previous social studies textbooks. The purpose is to solidify the research findings. The findings derived in result of analysis and assessment of data was reviewed together with 5 teachers from the group responding to the interview form. Again, the findings were reviewed together with a researcher specialising in social studies teaching. It can be argued that review of study findings together with other educators and researchers contributes to validity of the study.

\section{Findings}

As detailed under method section, assessment of content of the current textbook was based on teachers' responses to open ended questions. The content systematic of this heading was shaped according to open ended questions. Findings were revealed and interpreted based on analysis of the responses given to interview form questions.

\subsection{Compatibility of the Subjects in the Textbook to the Student Level}

The teachers' responses to the question "Are there any subjects in the textbook which are not compatible with the student level?" are as seen in Table 1. A large part, 20 of 28 interview participants, stated that there is a subject or subjects which are not compatible with the student level. Among the interview participants 9 of the 11 female teachers and 11 of the 17 male teachers have stated that there is a subject or subjects which are not compatible with the student level. Responses of teachers who stated existence of some omissions or errors in context of the question above are listed below in order to determine the subject incompatible with student level and reasons of this incompatibility. 
Table 1 . Are there any subjects in the textbook which are not compatible with the student level?

\begin{tabular}{lll}
\hline Participants & Yes & No \\
\hline E4, E5, E6, E7, E9, E10, E11, E12, E13, E14 E15 & X & \\
K1, K2, K3, K4, K6, K7, K8, K9, K10 & & \\
E1, E2, E3, E8, E16, E17 & X \\
K5, K11 & & \\
\hline
\end{tabular}

Note: Among the participants of the research, female teachers were coded as "k" and male teachers were coded as "e". Female and male teachers were numbered in their own groups.

E4: "The Ancient civilisations subject placed in Unit 2 should not be in the grade 5 textbook, even grade 6 students have trouble in grasping this subject."

E5: "I believe Anatolian and Mesopotamian civilisations subject is too heavy for grade 5 level. Because history subjects are too abstract for grade 5 students. It can be presented in a story telling language. Also, different visuals should be used."

E6: "Centralised government (active citizenship learning unit, government of my home subject) is above the student level."

E9: "In the culture and heritage learning unit, learning about civilisations subject I believe it would be more appealing to present the subject with a method caricaturising each civilisation, rather than a straight text narration, to enable the student to be more active and adapt to the subject more easily. Also, I believe the visuals in this subject section are falling short of consolidating the narration and holding attention. "

E10: "The students have difficulty with the civilisations subject. It shows a complicated design. Information on civilisations subject could have been placed in rectangular boxes in a way similar to the design of the beauties of our environment subject (people, places and environments learning unit)."

E11: "There are difficulties in teaching Anatolian and Mesopotamian civilisations in the culture and heritage learning unit. Inclusion of these civilisations in grade 5 learning unit has made the learning more difficult. The path of teaching contributions of civilisations in the most basic form should be taken. For example, Lydian's have invented the money, Sumerians have invented writing, etc. It would be more appropriate to place active citizenship learning unit, government of my home subject in program of next grade. "

E12: "Learning about civilisations subject in the culture and heritage unit is not compatible with the student level. Limits of the subject are not clearly determined; the information is too much and difficult for this age level."

E13: "Some unnecessary details are provided regarding Anatolian and Mesopotamian civilisations. Syllabus can be enriched with some more visuals and made more fun in the style of popular history telling. Some basic concepts (e.g. ports) can be taken into account in the regions of our country unit. I also believe it is unnecessary to force the student to memorise all mountains and plains in all regions."

E14: "Subjects are compatible with student level in general. However, the excessive amount of information contained in narration of the Anatolian civilisations subject creates difficulties. The reason for these difficulties is the fact that grade 5 students cannot yet leave their primary school habits behind."

K1: "The travel into history (Anatolian and Mesopotamian civilisations) and from past to today subjects in the culture and heritage unit are too abstract."

K2: "Our rights and responsibilities subject is not sufficiently objectified. The $6^{\text {th }}$ learning unit on active citizenship is not simplified down to grade 5 student level."

K3: "The travel into history subject in the culture and heritage learning unit is far from student level in regard of its narration style. The visuals are also incompatible with the student level and are perceived by the students as boring and meaningless. The information could have been made more appealing with a story telling style and catchy caricatures."

K4: "Ancient civilisations subject is far beyond the level of grade 5 students."

K6: "My home and government of my home, right to participate in government and freedom of thought subjects under the $6^{\text {th }}$ Unit (active citizenship) are too abstract."

K7: "Ancient civilisations subject is not compatible with grade 5."

K8: "Global connections subject is not compatible. Because this subject is too abstract for the student. " 
K9: "The social studies textbook is not prepared simple enough for grade 5 students who just finished primary school. Subjects are too heavy for student level."

K10: "I observed that students had difficulty in pronunciation and learning of some concepts in the ancient civilisations subject. Concepts like Ziggurat, Şamran, etc. are very difficult for children to grasp."

In assessment of the teacher responses above, it is seen that 12 of the 20 teachers opining "the textbook contains subjects incompatible with student level" view inclusion of the learning about civilisations (Anatolian and Mesopotamian civilisations) subject under the culture and heritage learning unit or the form of its inclusion with doubt. While some of these teachers believe this subject should not be included in grade 5, some believe that the same subject could belong to the textbook with better objectification like a story telling style language, better visuals, etc. making the subject more compatible with student level. According to the responses above, a very small number of teachers believe the government of my home subject under the active citizenship learning unit is not compatible with student level. Unlike the current program, the subject of Anatolian and Mesopotamian civilisations was placed in grade 6, and not in the culture and heritage learning unit covering history subjects more heavily, but in the life on earth subject under the people, places and environments learning unit in the 2005 social studies teaching program (Teaching and Education Committee, 2005). Looking farther back, it is seen that this subject was placed as a grade 4 subject in 1990 and 1968 social studies teaching programs (Ambarl1, 2010, 83; Keskin, 2002, 205). Through time this subject was included in program of various grades. Today, if this subject is included in grade 6 syllabus as it was some time before, this subject would be added to the subjects of Turks in myths and scriptures, birth and growth of Islam, Islam and Turks, a new home Anatolia, and paths directing history (Y1lmaz et al., 2018, 40-84). In this case, the program could end up with too many history subjects and lecture hours could become insufficient. As it is pointed out in responses of many teachers participating in the research, the better option is having this subject again in grade 5 program but using a language more compatible with student level for conveying the subject information to the student. In general, the teachers believe most of the learning units are compatible with the student level.

\subsection{Sufficiency of Current Information in the Textbook}

In examination of Table 2 regarding the responses to the question "Do you believe there is sufficient current information in the textbook?", it is seen that a large part, 20 of the participating teachers, responded yes. 8 of the teachers have expressed that the textbook contained some omissions and errors in regard of inclusion of current information and fulfilment of the principle of using current information. Responses of these teachers are listed below to provide a better understanding of negative aspects in regard of current information in the textbook:

Table 2. Presence of current information in the textbook

\begin{tabular}{lll}
\hline Participants & There are omissions & Sufficient \\
\hline K2, K3, K11 & X & \\
E10, E12, E13, E15, E17 & & \\
K1, K4, K5, K6, K7, K8, K9, K10 & $X$ \\
E1, E2, E3, E4, E5, E6, E7, E8, E9, E11, E14, E16 & \\
\hline
\end{tabular}

K2: "An attempt was made to support many subjects with current information, but there are many knowledge errors, and some information which has changed is not updated. This can be overlooked by the students and cause errors in learning. For example, even though inventor of telephone was changed as Antonio Meucci 16 years before, it is still included as G. Bell in the textbook."

K3: "Information on some recent findings or news on some excavations could be added under the culture and heritage learning unit. Science, technology and society learning unit, accurate and reliable information subject could be supported with many current subjects."

K11: "I believe current subjects are insufficient. Current subjects in science and technology can be added."

E10: "Current electronic devices are given a very small presence in the science and technology learning unit. Technological devices could be given a larger part in this unit (e.g. smartphones, tablets, smart watches, etc.)"

E12: "I believe more current subjects could be used. More modern information could also be included in the production, distribution and consumption unit."

E13: "In this age of science and interaction the textbook should cover the concept of privacy for our youth who are in the claws of social media." 
E15: "I believe there aren't enough current subjects. Information on global warming could be added."

E17: "There is no current subject. Newspaper clips could be added."

In examination of the above listed teacher responses expressing presence of some problems regarding current information, it is seen that the general opinion is current information, subjects and visuals in the science, technology and society learning unit are insufficient. In regard of the sentiment of the teacher coded E17 arguing newspaper clips could be added, it is seen that many subjects in the textbook include newspaper clips already (Şahin, 2018, 88-90). However, a large part of the teachers finds the textbook sufficiently current. In addition, the best way to alleviate problems regarding the measure of current information in the social studies textbook or how current the textbook is would be answered by response of one participant (E15), stating, "as use of technology increases in education teachers become more able to supplement the parts, they find incomplete."

\subsection{Suitability of Content Systematic of the Textbook}

In examination of Table 3 containing teachers' responses to the question "How do you find the content systematic of the textbook?" or "Do you find ordering of the subjects appropriate?" it is found that 16 teachers find the content systematic appropriate, while 12 don't. In order to better understand responses of teachers who express the content systematic is not appropriate and there are some problems in ordering of the subject, first the learning units which are same for all classes should be listed in order. These are: 1- Individual and society; 2- Culture and Heritage; 3- People, places and environment; 4- Science, technology and society; 5- Production, distribution and consumption; 6- Active citizenship; 7Global connections (Teaching and Education Committee, 2018, 11-12).

Table 3. Suitability of content systematic

\begin{tabular}{lll}
\hline Participants & Suitable & Not Suitable \\
\hline $\mathrm{K} 2, \mathrm{~K} 5, \mathrm{~K} 8, \mathrm{~K} 9, \mathrm{~K} 11$ & $\mathrm{X}$ & \\
$\mathrm{E} 3, \mathrm{E} 4, \mathrm{E} 5, \mathrm{E} 6, \mathrm{E} 7, \mathrm{E} 9, \mathrm{E} 11, \mathrm{E} 13, \mathrm{E} 14, \mathrm{E} 16, \mathrm{E} 17$ & & $\mathrm{X}$ \\
$\mathrm{K} 1, \mathrm{~K} 3, \mathrm{~K} 4, \mathrm{~K} 6, \mathrm{~K} 7, \mathrm{~K} 10$ & & \\
$\mathrm{E} 1, \mathrm{E} 2, \mathrm{E} 8, \mathrm{E} 10, \mathrm{E} 12, \mathrm{E} 15$ & & \\
\hline
\end{tabular}

Teachers' negative responses to the question regarding content systematic of the textbook and some summary explanations regarding these responses are as follows:

K1: "There no certain systematic in this textbook. Each unit is handled in and on its own. The science, technology and society unit could be placed at the end and expanded more. Looking at the ordering, it looks like current ordering prevented this." Focus on information in a different field in each unit of the textbook may lend to the idea that there is no content systematic in the textbook. Each unit in the social studies textbook constitutes a whole in itself. However, unlike in a high school geography textbook or a middle school mathematics textbook, units do not follow each other in regard of content.

K3: "First, in order of learning unit it would be more appropriate to place the people, places and environments learning unit after the individual and society learning unit. This should have been followed by the culture and heritage learning unit and active citizenship learning unit. The first subject under the active citizenship learning unit should have been my home and government of my home subject, rather than the public servants subject." This teacher's argument for placing the "people, places and environments" learning unit which contain more objective subjects after the "individual and society" learning unit largely comprising of abstract subjects rather than the current "culture and heritage" learning unit which generally comprises of abstract subjects' carrier some merit in regard of student motivation. In addition, this teacher's suggestion that government of my home subject should be the first one under the active citizenship learning unit can be seen congruent with the principle of near-to-far.

K4: "Placing the science, technology and society unit at the last place would be more appropriate. Placing the production, distribution and consumption unit after the people, places and environments would also be better." This teacher's suggestion of teaching "production, distribution and consumption" and "people, places and environments" learning units one after another could be based on the fact that both these two units containing subjects belonging or related to geographic sciences. If subjects under two learning units constitute continuation of each other, teaching them one after another can be considered in order to avoid discontinuity.

K6: This participant suggests the following order for learning units: "1- Individual and society; 2- People, places and environments; 3- Culture and heritage; 4- Production, distribution and consumption; 5- Global connections; 6- Science, technology and society; 7- Active citizenship." Suggestion of this teacher is in parallel with the suggestion of the teacher coded K3. This teacher also suggests placing the 3rd learning unit after the 1st. 
K7: "Subject of rights is included in both the individual and society unit and the active citizenship unit. This subject could have been included in only one."

K10: "In regard of content order, the subject of prehistoric ages should be taught before teaching the ancient civilisations subject. This subject is included in grade 7 syllabus in our curriculum. I believe it should be taught in grade 5." Chronology, i.e. enabling the student to place historic events on a certain timeline, is important in history teaching. Only way to form this timeline in the mind of the student is to establish knowledge of prehistoric ages and ages through history. In this context, ages of history could be taught as the first subject in history content in school. Even though it is suggested only by one teacher, this opinion is important and should be deliberated.

E1: "Subjects like history, geography, etc. could be presented under a single heading in the textbook." In this response the teacher sees geography subject being dispersed under multiple learning units as a problem. However, the content assumed as belonging to geographic sciences by many researchers could also be accepted as subjects of disciplines like economy, commerce, politics, etc. Can placement of these subjects under different learning units strengthen the practice of known-to-unknown principle? Or would this lead to unnecessary repeats? These questions could be the subject of other scientific studies.

E2: "The subject of rights is distributed among multiple learning units. These subjects could be brought together under one unit." Teacher coded K7 also puts forward the same suggestion. This could be considered for avoidance of repeating.

E8: "Subjects on commerce could be gathered under the production, distribution and consumption learning unit, while subjects on rights could be gathered under the active citizenship learning unit."

E10: "The Individual and Society unit should be followed by the Active Citizenship unit."

E12: "The individual and society unit could be followed by the active citizenship unit." Also suggested by teacher coded E10, this opinion may originate from the idea of presented related subjects or subjects complementing each other one after another to ensure content continuity.

E15: "Ordering of some subjects is not appropriate. Content ordering should be from near-to-far and from objective to abstract."

In general, a large part of teachers finds the ordering of learning units in the social studies textbook suitable. However, opinions of teachers who do not find it so, while infrequent, could still be meaningful in regard of deliberation of problems about content, and for finding solutions and developing suggestions.

\subsection{Suitablity of Textbook Content in regard of Fields of Social Sciences}

Since social studies course is an interdisciplinary field, it contains information belonging to various branches of social sciences. In this context, sufficiency and distribution of knowledge from various social sciences in the social studies' textbook carries importance in regard of education. In examination of Table 4 containing teachers' responses to questions of "Is the textbook content distribution suitable in regard of fields of social sciences?" or "Which fields are insufficiently represented?" it is seen that 19 teachers express that content of the social studies textbook is suitable for fields of social science, while 9 teachers express it is not.

Table 4. Suitability of content distribution in regard of fields of social sciences

\begin{tabular}{lll}
\hline Participants & Suitable & Not Suitable \\
\hline E4, E5, E6, E7, E9, E11, E13, E15, E16, E17 & X & \\
K2, K4, K5, K6, K7, K8, K9, K10, K11 & & \\
E1, E2, E3, E8, E10, E12, E14 & & X \\
K1, K3 & & \\
\hline
\end{tabular}

E1:"Incompleteness of historic subjects is glaring."

E2: "Incompleteness of historic subject is significant."

E3: "I believe historic subjects are too few and should be increased some more."

E8: "Historic subjects are insufficient."

E10: "Subjects could be increased in fields of history and geography."

E12: "Branches of social sciences like law, psychology, sociology, social psychology should be included more in grade 5." 
E14: "There are some shortages of philosophical subjects in the social studies textbook."

$\mathrm{K} 1$ : "Content on natural disasters and environmental problems is left thin in the people, places and environments units."

K3: "While it would be expected included fields of sciences in the social studies textbook to be weighted towards history, it is seen that 14 subjects are on geography, 5 subjects are on history, and 9 subjects are on citizenship."

In examination of the responses above, it is seen that 6 of the 9 teachers who responded that content distribution in the textbook is not suitable in regard of fields of social sciences point out that history subjects are insufficient or few. In the social studies reaching programs or books used before 2005 information belonging to history and geography disciplines were rich and large in number. For example, this can be seen in middle school grade 2 textbook of Akşit (1979) and grade 4 and 5 supplementary social studies textbooks of Çalapala (1978). In fact, when we consider geography subjects in many learning units, there is no decrease in number of geography subjects in the current social studies textbooks. The subject headings in the social studies textbooks used in the past and the subject headings in the social studies textbooks of today are largely the same. However, the details and the time allotted for these subjects have changed. Before 2005 approximately half of the social studies books were given to history subjects, while only one of the 7 learning units in the textbook (culture and heritage) is mostly given to history subjects. The best explanation for the decrease in the content and time allotted to history subjects in the new social studies textbook in comparison to the old books is provided by one of the responses given to the open ended question by one teacher (K10), stating, "as social studies course content is connected to many sciences, this course includes information from each science."

\subsection{Sufficiency of the Information in the Textbook}

In examination of Table 5 showing frequencies of responses of teachers to the question "Does the textbook contain sufficient explanatory information on subjects?" it is seen that 17 teachers find the information in the textbook sufficient, 7 finds it insufficient, and 4 finds it excessive. Responses of teachers who find the information insufficient or excessive are detailed below:

Table 5. Sufficiency of the Information in the Textbook

\begin{tabular}{llll}
\hline Participant & Sufficient & Insufficient & Excessive \\
\hline K1, K2, K3, K4, K6, K7, K9, K11 & $\mathrm{X}$ & \\
$\mathrm{E} 1, \mathrm{E} 3, \mathrm{E} 6, \mathrm{E} 7, \mathrm{E} 8, \mathrm{E} 9, \mathrm{E} 10, \mathrm{E} 11, \mathrm{E} 14$ & & \\
K5, K10, K8 & & \\
E2, E4, E5, E15, E16 & $\mathrm{X}$ & \\
K8 & & $\mathrm{X}$ \\
E12, E13, E17, & & \\
\hline
\end{tabular}

K5: "While the subjects and units are well selected, the content is very lacking. Not satisfactory at all."

K10: "The people, places and environments learning unit should provide some more explanatory information regarding climate. The subject of regions is not found in the book."

E2: "Information is left short, and areas to be filled were left for the student to research. This may constitute a problem for students and classes lacking this qualification."

E4: "There is not information on all subjects. For example, there is not sufficient explanatory information on our symbols of sovereignty and freedom."

E5: "There is not sufficient explanatory information. The information part should be enriched with storytelling type narration suitable for the level."

E15: "There is not sufficient explanation in some subjects. Therefore, students cannot understand some subjects."

E16: "Explanatory information is insufficient, rendering the children unable to tell what they are learning for which purpose."

In examination of the responses above, it is seen that some teachers express insufficiency of information not in the context of a certain learning unit, but in the context of all. Below, the teacher responses regarding the form of information presented, rather than insufficiency or excessiveness of information, are listed below.

K2: "Explanatory information about the subjects is provided without scaling down for the student level. Rather than providing solid information, presenting a storytelling type of narration would make the subject more appealing for grade 5 level. The children are unable to grasp the newly introduced concepts." 
K6: "The content is explanatory, but care could be taken to make narration suitable for grade 5 level. The information could be told as a story."

E12: "Many units contain sufficient explanatory information. In fact, some units contain too in-depth explanations."

K8: "No, there is not sufficient information, because students are having trouble objectifying what they read. The information should be scaled down to an extent."

E13: "The explanatory information can be tiring and stifling for grade 5 age group. Instead striking and short mini information pieces can be presented in one part of the book."

E17: "Explanatory information is sufficient, and even too excessive at some points."

Based on the responses above, it is seen some teachers find some problems in the form of presentation of information in the textbooks. According to these teachers providing excessive information or dry information dumps is not a preferable method of teaching. Techniques like Storytelling, caricatures, information boxes also including small illustrations, newspaper clips, etc. carry importance for teachers in rendering the information more appealing and more objective for the student. In result, according to the opinions of the teachers there is no question of insufficient information in the social studies textbook in general. The information is sufficient, and even excessive according to some teachers. The important distinction presentation of the information in a manner appealing to grade 5 students, as detailed above.

\subsection{Suitability of the Textbook in regard of Local Environment Teaching}

Two different approaches emerge in the teacher responses to the question of "Is the textbook sufficient in regard of teaching of local environment subjects?" One of these is having the teacher establish a connection between the unit subject and the local environment. Having specific subjects for each local environment in the textbook would require printing a unique book for each province, which would be very hard. Responses of some teachers giving their opinion in this direction are as follows:

E9: "While there are many things that can be done in this regard, I also believe it is not possible to reach perfection, because our country is both very suitable for significant differences in climate, transport, etc. in short distances due to its physical characteristic, and home to cultural richness. A unique book would have to be printed for each county to reach this goal, which would not be very likely."

E11: "It is a positive step to base teaching on local environment in regard of historic works, natural resources, terrain shapes, natural disasters and economic activities. This way, it becomes easier for the student to recognise physical and social characteristics of their environment."

E12: "The responsibility falls to the teacher in this regard. Turkey spreads over a large geography, and therefore it is difficult to present local environment information for everybody."

E13: "I don't see any problem since the syllabus allows the teacher some flexibility in this regard. The teacher can overcome this problem by basing their teaching on the region they work in."

According to teachers' responses to the question "Is the textbook sufficient in regard of teaching of local environment subjects?" another approach requires preparation of books containing local environment information on basis of provinces and regions. Some responses under this approach are as follows:

K3: "Some examples from historic digs, artefacts or known and heard objective samples from the local environment of the student could be provided."

K5: "Local environment subjects are not included. Subjects like regions, agricultural products should be included."

E1: "There is no subject that can be thought to cover Samsun province."

E3: "There is not sufficient information on subjects related to the Black Sea region. More information could be added regarding subject of the Black Sea Region. "

E8: "There is no subject related to our province. Subjects suitable for this aspect, i.e. localised information, would sadly be obstructed by centralised testing requirements."

E16: "Local environment subjects are insufficient, and what is available is mostly only suitable for children in western provinces."

In the current social studies textbook, local environment teaching is included in the form of research and present activity in scope of the "people, places and environments" unit (Şahin, 2018, 74). In the context of this activity, the question of "What are the climate characteristics of your home?" constitutes an activity aimed towards getting the students to learn about their home region. The social studies textbook attempts to connect many subjects to the local environment in this manner. This can also be seen in the old social studies textbooks. For example, grade 4 social studies supplementary 
book of Çalapala printed in 1978 includes questions like "How do seasons go in our province and region?", etc. in relation to the subjects under our province and region unit (13). Such questions provide activities helping students to become informed about their local environment. Such activities were used both in the past and today to help students research and find information regarding their local environment. Otherwise, as stated by some teachers participating in the study interview, it would not be possible to include information for every province in context of various subjects in the social studies textbook. To provide unity and integrity across the entire country, social studies textbook includes a general content. As Sönmez also states, this content should be adjusted according to the natural and social conditions of the student $(2005,43)$. As a matter of fact, both program gains directives and the activities in the textbook whose examples are provided above provide flexibility and guidance to the teacher in regard of teaching of local environment subjects.

\subsection{Presence of Sufficient Visuals Compatible with the Content in the Textbook}

In examination of Table 6 showing the teachers' response to the question "Are there sufficient visuals compatible with the content of the textbook?" it is seen that 21 teachers pointed out some lack and made suggestions regarding compatibility and sufficiency of visuals. In a study assessing sufficiency of the content of a social studies textbook, the purpose of asking such a question to the teachers would be the fact that visuals are an element which objectifies and complements the book content. Responses of teachers who point out some lack and made suggestions regarding compatibility and sufficiency of visuals in the textbook are as follows:

Table 6. Sufficiency of visuals related to the subjects

\begin{tabular}{lll}
\hline & Insufficient & Sufficient \\
\hline E2, E3, E8, E9, E10, E11, E12, E14, E15 & X & \\
E16, E17 & & \\
K1, K2, K3, K4, K5, K6, K7, K9, K10, K11 & & X \\
E1, E4, E5, E6, E7, E13 & & \\
K8 & &
\end{tabular}

E2; "Visuals, tables and graphs are sufficient. However, the number of maps of different types can be increased."

E3; "The book is good in regard of visuals, but I would like to see more tables and graphs."

E8; "Visuals take too much space. It is doubtful visuals provided in abstract subjects like rights would add comprehensibility. The number of basic graphs and maps could be increased."

E9: "In the people, places and environments learning unit, effects of climate on human activities subject, the visuals in the textbook of previous year were more striking and explanatory. For example, when presenting the climate of Black Sea region, the wooden houses, tea gardens and forests were shown separately (climate effects). In this year's print such visuals are lacking. In addition, some visuals regarding climate characteristics could be presented in sequence across the year. For example, when teaching inland climate showing grass turning green with rains in the spring, turning yellow in the summer, and the early arrival of autumn and winter in company of visuals would provide better comprehensibility."

E10: "The bazaar picture on page 54 is insufficient to relate culture from past to today. A visual depicting the change through time could be used. Its lack is felt. On page 122 the visual regarding tourism are on a very basic level. A visual more clearly showing the hotels and the shore could be used. Printing quality and visual content of the book make us look for the last year's book. A better table could be created for the civilisations subject (page 35). On page 76, placement of two tables on a single page creates crowding. On page 77 the table on social characteristics could have been provided before the subject heading."

E11: "The book is compatible and sufficient in regard of visuals. Only, the textbook of previous year was made more beautifully in regard of visuals and simplicity of information in comparison to this year's book."

E12: "Some visuals are small, e.g. page 119 (About Economic Activities). It is difficult to establish the connection between some visuals and the content, e.g. page 39. For grade 5 visuals could be provided in larger form under a separate section at the end of the book."

E14: "Tables and graphs are not sufficiently used in the book. However, the book is supported well with pictures in comparison to the old book. There are also visual insufficiencies in the science, technology and society unit. There are incongruities between the visuals and the content in the production, distribution and consumption unit. Again, more tables and graphs could have been used in the production, distribution and consumption unit.

E15: "Visuals are sufficient. Tables and graphs could be needed in regard of the population subject." 
E16: "Pictures provided under the subject are generally connected to the content, but insufficient. More pictures and visuals should be used, and students should not be stifled with long texts."

E17: "Visuals are sufficient, tables and graphs are insufficient."

K1; "More visuals could have been used under the Culture and Heritage unit. Use of caricatures would have been more beneficial and explanatory."

K2; "More effective and current visuals should have been used in the Active Citizenship and the Culture and Heritage units. Use of tables in the Active Citizenship unit would help objectify this very abstract subject."

$\mathrm{K} 3$; "Use of tables and graphs in the Active Citizenship learning unit would be very appropriate in regard of objectification."

K4; "Visuals can be increased."

K5; "More tables and graphs should be included. Other types of visuals are sufficient."

K6; "Since active citizenship is an abstract unit, objectifying visuals and caricatures could have been used."

K7; "More visuals can be used in the Active Citizenship and the Culture and Heritage units."

K9: "Tables and graphs are insufficient in the production, distribution and consumption unit. There are problems in the connection between content and visuals in the science, technology and society unit."

K10: "Graphs and tables could be added under the people, places and environments unit."

K11: "Tables and graphs could be added under the production, distribution and consumption unit."

In examination of the responses above it is found that among the 21 teachers who express insufficiencies in and suggestions for the visuals in the textbook 11 have stated that tables and graphs are insufficient. This insufficiency is particularly expressed in regard of the production, distribution and consumption learning unit and the population subject. 6 teachers have especially pointed out the incongruity between the content and the visuals. To assess some of the teacher responses above in regard of content-visual incongruity, let us take the response of the teacher coded E10 stating "On page 77 the table on social characteristics could have been provided before the subject heading." On page 76 of the textbook two schematics are presented, one about physical factors affecting population distribution, and one about social factors affecting the same. Information regarding physical factors affecting population distribution, and factors affecting the same are provided immediately under these images (Şahin, 2018, 76-77). In their response to the open-ended question in the interview the teacher asks for the visuals to be placed at the start of the relevant subject heading, not as both images related to population distribution placed next to each other. This suggestion can be considered in regard of helping the student establish a connection between the content and the visual. Response of the teacher coded E9 can also be considered in the context of incongruity between content and visuals. Let us assess this teacher's statement of "For example, when presenting the climate of Black Sea region, the wooden houses, tea gardens and forests were shown separately (climate effects). In this year's print such visuals are lacking. In addition, some visuals regarding climate characteristics could be presented in sequence across the year." In the 2017 print textbook which is currently out of use the climate types experienced in our country were each separately considered along with their effects on life. Visuals related to characteristics and effects of each climate type were presented along with the conveyed climate type information (Evirgen et al., 2017, 72-74). In other words, the visuals reflecting effects of climate types were not presented after the content. In the currently used 2018 print textbook first information and visuals regarding characteristics of the climate types experienced in our country were presented, and then information and visuals regarding effects of these climate types on life were included. Presentation of climate characteristics and their effects on life together as seen in previous year's book would be more suitable in regard of content integrity and congruity between content and visuals. This way, the students can more easily comprehend the connection between characteristics of climate types and their effects. This situation which can be thought as a negative aspect of the current textbook is also found in other parts of the book. The economic activities subject under the "production, distribution and consumption" unit first provides information on each separate economic activity and the status of these economic activities in Turkey. Then effects of economic activities on professions are considered under another heading (Şahin, 2018, 118-124). Unlike this approach, it would be more appropriate in regard of content systematics to handle effects of a certain economic activity on profession under the information presented regarding that economic activity, rather than gathering effects of economic activities on professions under a separate heading.

In responses of teachers coded E9, E11 and E14 the 2017 prink textbook and currently used textbook are compared in regard of visuals and some other characteristics. The two books are essentially the same in regard of content headings. The difference is in the form of presentation of the content and the visuals. The visual abundance and particularly the number of photographs in the currently used social studies textbook is no less than the previous year's book. However, 
size of the photographs is smaller in comparison to those of previous year's book. The preoccupation with including more photographs related to the subject might have caused this result. However, comparing two books in regard of visual print quality it can said the previous book displays a higher quality in comparison to the current one. In conclusion, it can be said that larger size and better print quality of visuals like photographs in the old book makes this book more appealing and more comprehensible in regard of visual elements. In addition, the current book is more intensive in information in comparison to the previous year's book. Response of the teacher coded E11, stating, "The textbook of previous year was made more beautifully in regard of visuals and simplicity of information in comparison to this year's book" is the best reflection of the status.

According to the responses, while some insufficiencies are pointed out in regard of the visuals in the textbook, the book is generally found rich in visuals. In case of particular, i.e. stand-alone assessment of units, teachers' responses suggest that learning units like culture and heritage and active citizenship comprising more abstract subject could include more visuals.

\section{Argument and Conclusions}

The "learning about civilisations" subject under the "culture and heritage" learning unit of the social studies textbook can be seen as the prominent subject among those deemed not compatible with the student level. In the work of Taş (2007) assessing social studies textbooks, the partial Likert concentration in teacher responses to the statement "the historic facts and cultural heritage are presented in an objectified manner" provides a parallel to results of this research (526). The most important reason for incompatibility of this subject with student level is seen as the manner of presentation of the information. To render this subject compatible with student level and to make it more enjoyable for the students, a storytelling language can be used to present the information in the textbook. In addition, increasing the number of visual elements like caricatures, photographs, info boxes, etc. under such abstract subjects can render these subjects more enjoyable and comprehensible for the students. Opinion of Şahin (2004) stating "textbook should present abstract information to students in small doses, in a form as objectified, enjoyable and appealing as possible" also supports out suggestion (287). While not to the level of the situation with the learning about civilisations subject, there are also some problems with incompatibility with student level in regard of the active citizenship learning unit. Increasing the number and diversity of visuals related to this learning unit in the textbook could contribute to solution of these problems.

It can be said the book contain sufficient current subjects and information. Sever's (2013) opinion on the social studies textbooks stating, "the texts are enriched by taking advantage of current and periodic publications" is in parallel with results of this research $(21)$. Nalçacı $(2011,335)$ and Taş $(2007,527)$ have also reached parallel results in their studies. Since textbooks are generally printed for 5-year periods, some information in these books may lose their currency, which is normal. A great part of the responsibility falls to the teachers in this regard, i.e. in regard of following up on current information.

A large part of the teachers finds the ordering of units in the social studies textbook suitable. Both of the "individual and society" and the "culture and heritage" learning units contain a large number of abstract subjects. Instead of placing these two learning units one after another, the more objective "people, places and environments" unit could be placed between the two.

The distribution of textbook content according to fields of social sciences is suitable. In the current textbook geography-related subjects are heavily found in many learning units, while history subjects are mostly gathered under one learning unit. Presence of geography subjects under many learning units is related to the characteristics of geographic sciences. Since geography is an interdisciplinary science, its content is shared with or related to many other sciences, and thus the importance of this science in the social studies has not waned through time. However, importance and weight of the history subjects in the social studies have decreased through time, while effect of current subjects like science and technology, etc. as well as citizenship subjects have increased. In the rapidly globalising and shrinking world it is normal for importance of such subjects to increase in social studies textbooks.

The textbook contains sufficient explanatory information. This result is in contradictions of the results of Sever's (2013, $28)$ and Gülersoy's $(2012,8)$ studies on social studies textbooks. This result might largely stem from the differences in content of the current social studies textbook and the textbooks examined by the abovenamed researchers. In addition, when assessing whether the information in the current social studies textbook is sufficient or not, we should also consider Keçe's opinion stating "Textbooks are now designed with an approach leaving intensive information dump method behind, instead picking an approach which provides less information but also indicates ways of accessing more information" and keep in mind that this book is intended for students fresh out of primary school (41). Here, the form of the information is more important than the amount of information contained in the book. Rather than dry information, a content objectified with various visuals and using a storytelling style of language can be more appropriate for a social 
studies textbook. This is particularly important for learning units like "culture and heritage", "active citizenship" and "individual and society". Problems regarding language and narration style of the books pointed out by İncekara (2010, $53)$ and Taş $(2007,26)$ in their studies regarding social studies textbooks also support our argument.

The textbook allows teaching of local environment subjects thanks to various activities defines in the book. The teacher can help the students to gain knowledge about their local environment by performing these activities. It is not possible to include information specific to each province or county, i.e. to prepare a specific book for each student.

In general, the social studies textbook is rich in visuals. Incekara $(2010,60)$ and Sever $(2013,20)$ have revealed similar opinions in their research. However, more visuals could have used to better objectify the subjects in the active citizenship and the culture and heritage learning units in the textbook. Particularly, the number of tables and graphs under the production, distribution and consumption learning unit and those regarding population subject could be increased. In addition to photographs, more visuals like caricatures, tables, graphs, etc. should be included. The printing quality of visuals like photographs, etc. and the size of some visuals could be increased.

\section{References}

Akşit, N., Sanır, F., \& Asal, T. (1979). Social Studies Secondary School Textbook. İstanbul, National Education Printing House

Alaca, E. (2017). An Evaluation of Social Studies Course Books. Education and Society in the 21st Century, 6(18), 759-785.

Alvermann, D. E., \& Moore, D. W. (1991). Secondary School Reading. In R. Barr, M. Kamil, P. Mosenthal \& P. D. Pearson (Eds.), Handbook of Reading Research, 2, 951-983.

Ambarl1, A. (2010). Elementary Education Social Studies Curriculum in Turkey Modifications. Corrections, Updating (Unpublished Master Thesis). Selçuk University Institute of Educational Sciences, Konya.

Baştürk, M. (2006). History of Textbooks. In Ö. Demirel \& K. Kıroğlu (Eds.), Subject Field Textbook Review, Pegem A. Publishing.

Bayrakçı, M. (2005). Course Books and Free Course Book Distribution Project for Primary Schools. National Education Journal, 165, 3-13, Ankara.

Çalapala, R. (1978). Social Studies 4th Grade Supplementary Textbook. İnkılap and Aka Bookstores, İstanbul.

Çalapala, R. (1978). Social Studies 5th Grade Supplementary Textbook. İnkılap and Aka Bookstores, İstanbul.

Ceyhan, E., \& Yiğit, B. (2003). Subject Field Textbook Review. Anı Publishing, Ankara.

Dove, M. (1998). The Textbook in Education. The Delta Kappa Gamma Bulletin, 64(3), 24-30.

Evirgen, Ö., Özkan, J., Öztürk, S., \& Özdural, Z. (2017). Social Studies 5th Grade Textbook. Publications of the Ministry of Education, Ankara.

Gökkaya, K., \& Oruç, Ş. (2003). An Example of Using Visual Material in Social Studies Books: Photo. In C. Şahin (Eds.), Subject Field Textbook Review Guide Social Studies, Gündüz Education and Publishing, Ankara.

Gülersoy, A. E. (2012). The Examining of the Social Studies Textbooks in Terms of Some Features in the Research of the Ideal Textbook. International Journal of New Trends in Arts, Sports \& Science Education (IJTASE), 2(1), 8-26.

Güneş, H., \& Çelikler, D. (2010). Opinions of Students on the Textbook Analysis in Science Education Course. Journal of the Institute of Social Sciences, 5, 81-89.

Incekara, S., \& Karatepe, A. (2010). The Opinions of Teacher Candidates of Social Sciences About Textbooks Depending on the New Curriculum. Marmara Geographical Review, 21, 46-64.

İşman, A. (2005). Teaching Technologies and Material Development. Sempati Publishing and Pegem A. Publishing, Ankara.

Karabacak B., \& Turan, İ. (2007). The Assesment of Primary School Social Sciences Books According to Classroom Teacher Candidates' View. Atatürk University Journal of Kazım Karabekir Education Faculty, 16, 209-233.

Keçe, M. (2013). Learning-Teaching Process in Social Studies Books. In B. Akbaba (Eds.), Subject Field Textbook Review Guide Social Studies, Pegem Academy.

Keser, H. (2004). Evaluation of the Computer Course Textbooks Used in the 4th Grade of Primary School in Terms of Design Principles. The Journal of Turkish Educational Sciences, 2(3), 261-280.

Keskin, Y. (2002). Social Studies Education Curriculums Analyze and Compare from Second Constitutional Period to Nowadays in Turkey (Unpublished Master Thesis). Marmara University Institute of Educational Sciences, İstanbul. 
Kılıç, A., \& Seven S. (2007). Subject Field Textbook Review. Pegem Publishing, Ankara.

Kılıç, D. (2006). Place of Course Book in Teaching. In Ö. Demirel \& K. Kıroğlu (Eds.), Subject Field Textbook Review, Pegem A. Publishing, Ankara.

Köksal, N., F. (2012). Selection and Regulation of Teaching Content. In Ş. Tan (Eds), Teaching Principles and Methods, Pegem Academy, Ankara.

Küçükahmet, L. (2004). Place of Course Book in Educational Programs. In L. Küçükahmet (Eds), Subject Field Textbook Review Guide, Nobel Publishing and Distribution.

M.E.B. (2005). Elementary School Social Studies Course 6th and 7th Grade Curriculum. Ankara.

M.E.B. (2018). Social Studies Course Curriculum. Ankara.

Nalçacı, A. (2011). Evaluation of Elementary School 5th Grade Social Studies Textbook in Accordance with Teachers' Opinions (Erzurum Sample). Journal of Graduate School of Social Sciences, 15(2), 321-335.

Öcal, A., \& Yiğittir, S. (2007). The Evaluation of Social Studies Textbooks According to Elementary School's Teacher (Kırıkkale Sample). Ahi Evran University Journal of Kirşehir Faculty of Education, 8(1), 51-61.

Önal, H., \& Kaya, N. (2013). The Evaluation of Social Studies Textbooks of Fourth and Fifth Grad. Balikesir University Journal of Social Sciences Institute, 16(29), 21-37.

Özgen, N. (2016). Collection and Analysis of Data in Qualitative Research. In N. Özgen (Eds), Research Methods and Techniques in Human Geography, Pegem Academy.

Patton, M. Q. (2014). Qualitative Research \& Evaluation on of Social Studies Textbooks of Fourth and Fifth Grad. Balikesir University Journal of Social Sciences Institute, 16(29), 21-37.

Pinto, L. E. (2007). Textbook Publishing, Textbooks, and Democracy: A Case Study. Journal of Thought, 40(3), 99-121.

Şahin, E. (2018). Social Studies 5th Grade Course Book. Anadolu Publishing, Ankara.

Sahin, T. Y. (2004). Teaching Materials and Technologies. In C. Öztürk\& D. Dilek (Eds.), Teaching of Life Science and Social Studies, Ankara: Pegem A. Publishing.

Sever, R., \& Koçoğlu, E. (2013). Social Studies Textbooks Social Studies Teachers' Opinions on the Topics of Geography/Central District, Case of Diyarbakır. Electronic Journal of Social Sciences, 12(45), 17-34.

Sönmez, V. (2005). Teacher's Guide of Teaching Life Science and Social Studies. Anı Publishing, Ankara.

Sönmez, V. (2011). Teaching Principles and Methods. Anı Publishing, Ankara.

Taş, M. A. (2007). Determining Teachers' Opinions about New Social Studies Textbooks. Selcuk University Journal of Institute of Social Sciences, 17, 519-532.

Taşdemir, M. (2011). Teaching Planning. In B. Duman (Eds.). Teaching Principles and Methods. Anı Publishing.

Tertemiz, N., Ercan, L., \& Kayabaşı, Y. (2004). Textbook and Its Importance in Education. In L. Küçükahmet (Eds.), Subject Field Textbook Review Guide, Nobel Publishing and Distribution.

Ulusoy, K. (2008). Textbooks in Social Studies. In B. Tay \& A. Öcal (Eds), Teaching Social Studies with Special Teaching Methods, Pegem A. Academy, Ankara.

Yılmaz, F., Bayraktar, H., \& Özden, M. et al. (2018). Social Studies 6th Grade Textbook. Publications of the Ministry of Education, Ankara.

\section{Copyrights}

Copyright for this article is retained by the author(s), with first publication rights granted to the journal.

This is an open-access article distributed under the terms and conditions of the Creative Commons Attribution license which permits unrestricted use, distribution, and reproduction in any medium, provided the original work is properly cited. 